\title{
Rapid eye movement sleep deprivation induces an increase in acetylcholinesterase activity in discrete rat brain regions
}

M.A.C. Benedito and R. Camarini

\author{
Departamento de Psicobiologia, Universidade Federal de São Paulo, \\ São Paulo, SP, Brasil
}

\section{Correspondence \\ M.A.C. Benedito \\ Departamento de Psicobiologia \\ Universidade Federal de São Paulo \\ Rua Botucatu, 862 \\ 04023-062 São Paulo, SP \\ Brasil}

Research supported by FAPESP and Associação Fundo de Incentivo à Psicofarmacologia (AFIP). R. Camarini was the recipient of a FAPESP fellowship.

Received December 6, 1999 Accepted September 25, 2000

\section{Abstract}

Some upper brainstem cholinergic neurons (pedunculopontine and laterodorsal tegmental nuclei) are involved in the generation of rapid eye movement (REM) sleep and project rostrally to the thalamus and caudally to the medulla oblongata. A previous report showed that 96 $\mathrm{h}$ of REM sleep deprivation in rats induced an increase in the activity of brainstem acetylcholinesterase (Achase), the enzyme which inactivates acetylcholine (Ach) in the synaptic cleft. There was no change in the enzyme's activity in the whole brain and cerebrum. The components of the cholinergic synaptic endings (for example, Achase) are not uniformly distributed throughout the discrete regions of the brain. In order to detect possible regional changes we measured Achase activity in several discrete rat brain regions (medulla oblongata, pons, thalamus, striatum, hippocampus and cerebral cortex) after $96 \mathrm{~h}$ of REM sleep deprivation. Naive adult male Wistar rats were deprived of REM sleep using the flower-pot technique, while control rats were left in their home cages. Total, membrane-bound and soluble Achase activities (nmol of thiocholine formed $\mathrm{min}^{-1} \mathrm{mg}$ protein ${ }^{-1}$ ) were assayed photometrically. The results (mean $\pm \mathrm{SD}$ ) obtained showed a statistically significant (Student $t$-test) increase in total Achase activity in the pons (control: $147.8 \pm 12.8$, REM sleep-deprived: $169.3 \pm 17.4$, $\mathrm{N}=6$ for both groups, $\mathrm{P}<0.025$ ) and thalamus (control: $167.4 \pm 29.0$, REM sleep-deprived: $191.9 \pm 15.4, \mathrm{~N}=6$ for both groups, $\mathrm{P}<0.05$ ). Increases in membrane-bound Achase activity in the pons (control: $171.0 \pm 14.7$, REM sleep-deprived: $189.5 \pm 19.5, \mathrm{~N}=6$ for both groups, $\mathrm{P}<0.05$ ) and soluble enzyme activity in the medulla oblongata (control: $147.6 \pm 16.3$, REM sleep-deprived: $163.8 \pm 8.3, \mathrm{~N}=6$ for both groups, $\mathrm{P}<0.05$ ) were also observed. There were no statistically significant differences in the enzyme's activity in the other brain regions assayed. The present findings show that the increase in Achase activity induced by REM sleep deprivation was specific to the pons, a brain region where cholinergic neurons involved in REM generation are located, and also to brain regions which receive cholinergic input from the pons (the thalamus and medulla oblongata). During REM sleep extracellular levels of Ach are higher in the pons, medulla oblongata and thalamus. The increase in Achase activity in these brain areas after REM sleep deprivation suggests a higher rate of Ach turnover.

\section{Key words}

- REM sleep deprivation

- Acetylcholinesterase

- Brain regions

- Thalamus

- Medulla oblongata

- Pons 


\section{Introduction}

Brainstem cholinergic neurotransmission is involved in the generation and maintenance of rapid eye movement (REM) sleep. There is strong evidence that pontine cholinergic and cholinoceptive neurons, interacting in coordination, trigger and maintain REM sleep (for a review, see 1). Higher cholinergic activity during REM sleep has been shown by means of microdialysis. Higher acetylcholine (Ach) output occurs in the pons (2), medulla oblongata (3), hippocampus and cerebral cortex (4) in cats, and in the thalamus in rats (5), during REM sleep as compared to synchronized sleep.

Previous data have shown an increase in the activity of acetylcholinesterase (Achase), the enzyme that inactivates Ach in the synaptic cleft (6), in the brainstem of rats deprived of REM sleep for $96 \mathrm{~h}$ (7). There were no changes in the enzyme's activity in the whole brain or cerebrum. There are significant regional differences in the levels of the components of cholinergic nerve endings in the brain. Levels of choline and Ach (8), choline acetyltransferase and Achase activity $(8,9)$ and cholinergic receptors (10) are not uniformly distributed throughout the regions of the brain. These regional differences indicate differences in the density and activity of cholinergic nerve endings. This suggests that regional studies are most appropriate to detect changes in brain cholinergic neurotransmission after REM sleep deprivation. In order to address this issue we studied the effect of $96 \mathrm{~h}$ of REM sleep deprivation on Achase activity in several discrete brain areas (medulla oblongata, pons, thalamus, striatum, hippocampus and cerebral cortex) in rats. These brain regions were chosen because of their different cholinergic inputs. Cholinergic neurons located in the pons project to the thalamus and medulla oblongata, whereas the cholinergic inputs to the hippocampus and cerebral cortex arise in cholinergic nuclei located in the basal fore- brain. Striatum cholinergic innervation, on the other hand, is mostly due to local interneurons (for reviews, see 1,11).

\section{Material and Methods}

\section{Animals}

Three-month-old, naive adult male Wistar rats, bred in our colony, and weighing 250$300 \mathrm{~g}$ were used in this study. After weaning, the rats were housed in wire-mesh cages in groups of 3 and kept in a room with a controlled light-dark cycle (lights on from 7 a.m. to 7 p.m. $)$ and temperature $\left(22 \pm 2^{\circ} \mathrm{C}\right)$. The animals had free access to tap water and Purina ${ }^{\circledR}$ lab chow until the time of sacrifice. The handling of animals was limited to room and cage cleaning.

\section{REM sleep deprivation}

REM sleep deprivation started at 9 a.m. Animals were placed individually in water tanks on a small flower-pot for $96 \mathrm{~h}$. The flower-pot was $6.5 \mathrm{~cm}$ in diameter surrounded by water $2 \mathrm{~cm}$ below its surface. The control rats were kept individually in their home cages. A large platform control group, to control the stress of the procedure, was not included as it has been shown that there is no change in Achase activity in such groups $(7,12)$.

\section{Enzyme assay}

After decapitation, the brains were excised and kept on a Petri dish cooled with crushed ice. The brains were washed with cold isotonic saline to remove blood and the brain regions were then immediately dissected and weighed. The tissue was kept in cold $0.32 \mathrm{M}$ sucrose (pH 7.4 with Tris base).

Homogenates $(5 \% \mathrm{w} / \mathrm{v})$ were prepared using glass homogeneizer tubes and a Teflon $^{\mathrm{TM}}$ motor-driven pestle. The homogenates were centrifuged at $900 \mathrm{~g}$ for $10 \mathrm{~min}$ at 
$4^{\circ} \mathrm{C}$ and the supernatants were collected and centrifuged at $100,000 \mathrm{~g}$ for $60 \mathrm{~min}$ at $4^{\circ} \mathrm{C}$ (13). The supernatants from this step were the source of soluble Achase and the resulting pellets were resuspended in the original volume with cold $0.32 \mathrm{M}$ sucrose. The latter preparation was the source of membranebound Achase. Enzyme activity was also assayed in the $900 \mathrm{~g}$ supernatant (total enzyme activity). Homogenates were kept at $-20^{\circ} \mathrm{C}$ until they were assayed.

Acetylcholinesterase activity was assayed according to Ellman et al. (14) as described in detail elsewhere (12). Acetylthiocholine was used as the substrate in a $1-\mathrm{mM}$ final assay concentration. The thiocholine formed was measured spectrophotometrically at 412 $\mathrm{nm}$. Proteins were assayed using bovine albumin as the standard (15).

The enzyme activity is expressed as nmol thiocholine formed $\mathrm{min}^{-1} \mathrm{mg}$ protein ${ }^{-1}$.

\section{Reagents}

All reagents were analytical grade from Sigma Chemical Co. (St. Louis, MO, USA) or Merck S.A. (Rio de Janeiro, RJ, Brazil). Twice-distilled water prepared in an all-glass apparatus was used throughout the assays.

\section{Statistical analysis}

The unpaired Student $t$-test was used for comparisons between groups, with the level of significance set at $\mathrm{P} \leq 0.05$.

\section{Results}

REM sleep deprivation induced a statistically significant increase in Achase activity in the brain regions listed in Table 1. Significant increases in soluble Achase activity were obtained in the medulla oblongata $(\mathrm{t}=2.12$, d.f. $=10, \mathrm{P}<0.05)$, in total $(\mathrm{t}=$ 2.44 , d.f. $=10, \mathrm{P}<0.025)$, and particulate enzyme activity $(\mathrm{t}=1.86$, d.f. $=10, \mathrm{P}<0.05)$ in the pons and in total Achase activity in the thalamus $(\mathrm{t}=1.82$, d.f. $=10, \mathrm{P}<0.05)$.

There were no statistically significant differences in Achase activity (total, particulate or soluble) in the hippocampus, striatum or cerebral cortex $(\mathrm{P}>0.05$ for all of the comparisons) (Table 2).

\section{Discussion}

It has previously been shown that $96 \mathrm{~h}$ of REM sleep deprivation does not change total Achase activity in the whole brain or cerebrum of rats (7). However, the present re-

Table 1 - Specific activity of total, particulate and soluble acetylcholinesterase (Achase) in discrete brain regions involved in the generation of, or affected by, REM sleep, after REM sleep deprivation (REMSD).

Specific activity of Achase is expressed as nmol of thiocholine formed $\mathrm{min}^{-1} \mathrm{mg}$ protein $^{-1}$. Data are reported as the mean $\pm S D(N=6$ for all groups). Final acetylthiocholine concentration in the assays was $1 \mathrm{mM}$. $* \mathrm{P}<0.05$ and $* * \mathrm{P}<0.025$ vs control (Student t-test).

\begin{tabular}{lllcc}
\hline \multirow{2}{*}{ Brain region } & Treatment & \multicolumn{3}{c}{ Enzyme activity } \\
\cline { 3 - 5 } & & \multicolumn{1}{c}{ total } & particulate & soluble \\
\hline Medulla oblongata & Control & $122.1 \pm 7.1$ & $139.6 \pm 7.5$ & $147.6 \pm 16.3$ \\
& REMSD & $122.5 \pm 5.5$ & $138.7 \pm 5.4$ & $163.3 \pm 8.3^{*}$ \\
Pons & Control & $147.8 \pm 12.8$ & $171.0 \pm 14.7$ & $141.5 \pm 31.0$ \\
& REMSD & $169.3 \pm 17.4^{* *}$ & $189.5 \pm 19.5^{*}$ & $158.3 \pm 27.2$ \\
Thalamus & Control & $167.4 \pm 29.0$ & $158.8 \pm 32.5$ & $106.7 \pm 23.0$ \\
& REMSD & $191.9 \pm 15.4^{*}$ & $173.1 \pm 11.2$ & $128.1 \pm 39.5$
\end{tabular}

Table 2 - Specific activity of total, particulate and soluble acetylcholinesterase (Achase) in discrete brain regions of REM sleep-deprived (REMSD) rats.

Specific activity of Achase is expressed as nmol of thiocholine formed $\mathrm{min}^{-1} \mathrm{mg}$ protein $^{-1}$. Data are reported as the mean $\pm S D(N=6$ for all groups). Final acetylthiocholine concentration in the assays was $1 \mathrm{mM}$.

\begin{tabular}{lcccc}
\hline \multirow{2}{*}{ Brain region } & Treatment & \multicolumn{3}{c}{ Enzyme activity } \\
\cline { 3 - 5 } & & total & particulate & soluble \\
\hline Hippocampus & Control & $127.9 \pm 17.2$ & $141.7 \pm 15.5$ & $142.0 \pm 20.8$ \\
& REMSD & $126.6 \pm 14.5$ & $138.0 \pm 16.2$ & $123.9 \pm 20.1$ \\
Striatum & Control & $692.0 \pm 22.6$ & $815.1 \pm 75.4$ & $409.7 \pm 10.7$ \\
& REMSD & $690.4 \pm 20.1$ & $800.1 \pm 35.0$ & $403.0 \pm 79.9$ \\
Cerebral cortex & Control & $103.8 \pm 8.6$ & $124.3 \pm 7.4$ & $43.4 \pm 6.5$ \\
& REMSD & $102.8 \pm 8.9$ & $121.5 \pm 8.9$ & $46.0 \pm 8.6$
\end{tabular}


sults show that $96 \mathrm{~h}$ of REM sleep deprivation in rats induced a significant increase in Achase activity in the medulla oblongata, pons and thalamus, without affecting the enzyme's activity in the striatum, hippocampus or cerebral cortex. The present data agree with the reported heterogeneous distribution of Achase activity in different regions of the rat's brain $(8,9)$ and they also indicate the need to carry out assays in discrete brain areas rather than in large ones.

There are significant differences in Achase activity among discrete regions (8). These differences are also observed in smaller brain areas such as discrete nuclei (9). Therefore, the small significant differences (11 to $15 \%)$ in enzyme activity obtained in our study may be larger in more restricted brain areas, although to explore this possibility will require further experimentation.

The increase in Achase activity in the brainstem regions (pons and medulla oblongata) obtained in our study is in accordance with previous data which showed an increase in total enzyme activity in the whole brainstem of rats after $96 \mathrm{~h}$ of REM sleep deprivation (7). However, our results differ from another report which showed a decrease in free Achase activity in the medulla oblongata and pons and an increase in bound enzyme activity in the medulla oblongata after $96 \mathrm{~h}$ of REM sleep deprivation in rats (16). Although at this time there is no explanation for these discrepancies, it is likely that the different patterns of change obtained in the two sets of data are due to different methodological approaches in the preparation of the enzyme fractions used in the assays. For instance, we used a $900 \mathrm{~g}$ supernatant (freed of blood vessels and cell debris) to prepare the soluble and bound enzyme, whereas the other study used the whole homogenate as the source of free and bound enzyme (16). Furthermore, we did not use high $\mathrm{NaCl}$ concentrations or detergent to release bound Achase, whereas in the other study they did (16).
The pattern of change in Achase activity after $96 \mathrm{~h}$ of REM sleep deprivation obtained in our study showed that the increase in enzyme activity occurred only in the brain region where cholinergic neurons involved in REM sleep generation are located (the pons) and in brain regions receiving a cholinergic input (medulla oblongata, thalamus) from pontine cholinergic neurons $(1,11)$. The lack of change in enzyme activity in the striatum, hippocampus and cerebral cortex suggests that the other cholinergic nuclei which innervate these brain regions $(1,11)$ were not affected by REM sleep deprivation.

It has been demonstrated that Achase levels increase in neuromuscular junction and brain tissue as a result of an increased frequency of Ach-receptor interaction (17, 18). Higher output of Ach occurs in the pons (2), medulla oblongata (3) and thalamus (5) during REM sleep and it is possible that the pressure for REM sleep caused by deprivation leads to an overshoot in Ach release in an attempt to overcome the REM sleep deprivation. Therefore, the increase in Achase activity observed after REM sleep deprivation may be the result of an increased release of Ach above the normal levels needed to generate REM sleep. A decrease in muscarinic $\mathrm{M}_{2}$-type cholinergic receptor binding in the thalamus of rats deprived of REM sleep for $96 \mathrm{~h}$ (19) seems to support this hypothesis of increased synaptic Ach release.

The noradrenergic neurons of the locus coeruleus, located in the brainstem, decrease their firing rate in anticipation of REM sleep and almost cease firing during REM sleep, whereas a subset of cholinergic neurons in the pedunculopontine region of the brainstem increase their firing rate and seem to be involved in the generation of REM sleep (20). Therefore, there is a physiological imbalance between cholinergic and noradrenergic neurotransmission in the brainstem during REM sleep. It has been proposed that an imbalance between brain cholinergic/nor- 
adrenergic neurotransmission is involved in mood disorders. According to this hypothesis, depression is the result of overactive brain cholinergic neurotransmission and mania is the result of overactive noradrenergic neurotransmission (21). REM sleep deprivation has antidepressant effects in humans (22) and in rats it decreases immobility in the behavioral despair test, which has been used for the screening of antidepressive drugs (23). REM sleep deprivation induces a state of higher brain excitability (24) and a decreased sensitivity to cholinergic agonists, as demonstrated by a decrease in yawns (25). Depressed patients have disturbed REM sleep, as shown by a shorter REM sleep latency, more REM sleep episodes in the first part of the night and more eye movements during REM sleep (26). This disturbance in REM sleep is suggestive of a dysregulation of cholinergic neurotransmission in depression. Antidepressant treatments increase brain noradrenergic neurotransmission (27) and REM sleep deprivation also has this effect; for instance, it induces an increased availability of noradrenaline as evidenced by an increase in whole brain noradrenaline turnover (28), an increase in tyrosine hydroxylase mRNA and enzyme activity (29-31), a decrease in the activity of monoaminoxidase A $(32,33)$, a downregulation of beta-adrenergic receptors (34), and a decrease in the synthesis of cAMP stimulated by noradrenaline (35). These data may suggest a counteracting effect of REM sleep deprivation on the normal imbalance between cholinergic/noradrenergic neurotransmission observed during REM sleep. The increase in Achase activity obtained in the brainstem and thalamus and the reported decrease in cholinergic receptor binding (19) may be the expression of the changed interaction between cholinergic/noradrenergic neurotransmission in rats deprived of REM sleep.

There is a relationship between brainstem and basal forebrain cholinergic neu- rons in the control of sleep and wakefulness. Magnocellular regions of the basal forebrain are involved in the regulation of the sleepwake cycle and arousal seems to be mediated by basal forebrain cholinergic neurons (36). Brainstem cholinergic neurons (pedunculopontine and laterodorsal tegmental nuclei) project to the basal forebrain (37) and cholinergic basalis neurons project monosynaptically to the neocortex and regulate the EEG patterns characteristic of wakefulness and REM sleep $(36,38)$. Microinjection of carbachol, a cholinergic agonist, into the basal forebrain increases wakefulness, whereas microinjection into the pons induces a state resembling REM sleep (39). We have previously shown a significant decrease in membrane-bound Achase activity in the frontal cortex of REM sleep-deprived rats (12). In the present study there was no difference in Achase activity in the cerebral cortex. Cholinergic cerebral cortex innervation arises in the basal forebrain neurons (11). The frontal cortex receives its cholinergic input from cholinergic neurons located in the rostral nucleus basalis and substantia innominata, whereas the other cortical areas are innervated by cholinergic neurons located more caudally in the nucleus basalis and nucleus of the ansa lenticularis (11). The decrease in Achase activity in the frontal cortex (12) and the lack of change in enzyme activity in the cerebral cortex suggest an effect of REM sleep deprivation on a subpopulation of forebrain basal cholinergic neurons. The pattern of the effect of REM sleep deprivation on Achase activity (decreased activity in frontal cortex with no change in cerebral cortex and increased activity in pons, medulla oblongata and thalamus) seems to represent the functional complexity of cholinergic nuclei in the basal forebrain and brainstem and their role in different brain functions $(1,11,36,37,40)$.

In conclusion, we observed an increase in Achase activity after $96 \mathrm{~h}$ of REM sleep deprivation which was restricted to brain 
regions either involved in REM sleep generation or receiving cholinergic inputs directly from cholinergic nuclei involved in REM sleep generation. Further studies are needed to better understand the effects of REM sleep deprivation on cholinergic neurotransmission.

\section{References}

1. Rye DB (1997). Contributions of the pedunculopontine region to normal and altered REM sleep. Sleep, 20: 755-788.

2. Lydic R, Baghdoyan HA \& Lorinc S (1991). Microdialysis of cat pons reveals enhanced acetylcholine release during statedependent respiratory depression. American J ournal of Physiology, 261: R766R770.

3. Kodama T, Lay YY \& Siegel J M (1992). Enhancement of acetylcholine release during REM sleep in the caudomedial medulla as measured by in vivo microdialysis. Brain Research, 580: 348-350.

4. Marrosu F, Portas C, Mascia MS, Casu MA, Fa M, Giagheddu M, Imperato A \& Gessa GL (1995). Microdialysis measurement of cortical and hippocampal acetylcholine release during sleep-wake cycle in freely moving cats. Brain Research, 671: 329-332.

5. Williams J A, Comisarow J , Day J , Fibiger HC \& Reiner PB (1994). State-dependent release of acetylcholine in rat thalamus measured by in vivo microdialysis. J ournal of Neuroscience, 14: 5236-5242.

6. Brimijoin S (1983). Molecular forms of acetylcholinesterase in brain, nerve and muscle: Nature, localization and dynamics. Progress in Neurobiology, 21: 291322.

7. Thakkar M \& Mallick BN (1991). Effect of REM sleep deprivation on rat brain acetylcholinesterase. Pharmacology, Biochemistry and Behavior, 39: 211-214.

8. Stavinoha WB, Weintraub ST \& Modak AT (1974). Regional concentrations of choline and acetylcholine in the rat brain. J ournal of Neurochemistry, 23: 885-886.

9. Hoover DB, Muth EA \& J acobowitz DM (1978). A mapping of the distribution of acetylcholine, choline acetyltransferase and acetylcholinesterase in discrete areas of rat brain. Brain Research, 153: 295306.

10. Spencer J r DG, Horvath E \& Traber J (1986). Direct autoradiographic determination of $M_{1}$ and $M_{2}$ muscarinic acetylcholine receptor distribution in the rat brain: relation to cholinergic nuclei and projections. Brain Research, 380: 59-68.
11. Woolf N (1991). Cholinergic systems in mammalian brain and spinal cord. Progress in Neurobiology, 37: 475-524.

12. Camarini R \& Benedito MAC (1997). Rapid eye movement (REM) sleep deprivation reduces rat frontal cortex acetylcholinesterase (EC 3.1.1.7) activity. Brazilian J ournal of Medical and Biological Research, 30: 641-647.

13. Chubb IW \& Smith AD (1975). Isoenzymes of soluble and membrane-bound acetylcholinesterase in bovine splanchnic nerve and adrenal medulla. Proceedings of the Royal Society of London. B, Biological Sciences, 191: 245-261.

14. Ellman GL, Courtney KD, Andres-J r V \& Featherstone RM (1961). A new and rapid colorimetric determination of acetylcholinesterase activity. Biochemical Pharmacology, 7: 88-95.

15. Lowry $\mathrm{OH}$, Rosebrough NJ , Farr AL \& Randall RJ (1951). Protein measurement with the Folin phenol reagent. J oumal of Biological Chemistry, 193: 265-275.

16. Mallick BN \& Thakkar M (1992). Effect of REM sleep deprivation on molecular forms of acetylcholinesterase in rats. NeuroReport, 3: 676-678.

17. Fernandez $\mathrm{HL} \&$ Hodges-Savola $\mathrm{CA}$ (1992). Trophic regulation of acetylcholinesterase isoenzymes in adult mammalian skeletal muscles. Neurochemical Research, 17: 115-124.

18. Nitsch RM, Rossner S, Albrech C, Mayhans M, Enderich J, Schliebs R, Wegner $M$, Arendt $T \&$ von der Kammer H (1998). Muscarinic acetylcholine receptors activate the acetylcholinesterase gene promoter. J ournal of Physiology, 92: 257-264.

19. Nunes J r GP, Tufik $S \&$ Nobrega J N (1994). Decreased muscarinic receptor binding in rat brain after paradoxical sleep deprivation: an autoradiographic study. Brain Research, 645: 245-252.

20. Hobson JA, Lydic R \& Baghdoyan HA (1986). Evolving concepts of sleep cycle generation: from brain centers to neuronal populations. Behavioral and Brain Sciences, 9: 371-448.

21. J anowsky DS, El-Yousef MK, Davis J M \&
Sekerke HJ (1972). A cholinergic-adrenergic hypothesis of mania and depression. Lancet, II: 632-635.

22. Vogel GW, Vogel F, McAbec RS \& Thurmond AJ (1980). Improvement of depression by REM sleep deprivation. Archives of General Psychiatry, 37: 247-253.

23. Porsolt RD, Anton G, Blovet $N$ \& J olfre $M$ (1978). Behavioral despair in rats: a new model sensitive to antidepressant treatments. European J ournal of Pharmacology, 47: 379-391.

24. Cohen HB \& Dement WC (1965). Sleep: changes in threshold to electroconvulsive shock in rats after deprivation of "paradoxical" phase. Science, 150: 1318-1319.

25. Tufik S, Troncone LRP, Braz S, Silva-Filho AR \& Neumann B (1987). Does REM sleep deprivation induce subsensitivity of presynaptic dopamine or postsynaptic acetylcholine receptors in the rat brain? European J ournal of Pharmacology, 140: 215-219.

26. Benca RM, Okawa M, Uchiyama M, Ozaki S, Nakajima T, Shibui K \& Obermeyer WH (1997). Sleep and mood disorders. Sleep Medicine Reviews, 1: 45-56.

27. VetulaniJ (1991). The development of our understanding of the mechanism of action of antidepressant drugs. Polish J ournal of Pharmacy and Pharmacology, 43: 323-338.

28. Schildkraut JJ \& Hartman E (1972). Turnover and metabolism of norepinephrine in rat brain after 72 hours on a D-deprivation island. Psychopharmacology, 27: 17-27.

29. Sinha AK, Ciaranello RD, Dement WC \& Barchas J D (1973). Tyrosine hydroxylase activity in rat brain following "REM" sleep deprivation. J oumal of Neurochemistry, 20: 1289-1290.

30. Basheer R, Magnes M, McCarley RW \& Shiromani PJ (1998). REM sleep deprivation increases the levels of tyrosine hydroxylase and norepinephrine transporter mRNA in the locus coeruleus. Molecular Brain Research, 57: 235-240.

31. Porkka-Heiskanem J, Smith SE, Taira T, Urban J H, Levine J E, Turek RW \& Stenberg $D$ (1995). Noradrenergic activity in rat brain during rapid eye movement sleep 
deprivation and rebound sleep. American J ournal of Physiology, 268: R1456-R1463.

32. Perez NM \& Benedito MAC (1997). Activities of monoaminoxidase (MAO) $A$ and $B$ in discrete regions of rat brain after rapid eye movement (REM) sleep deprivation. Pharmacology, Biochemistry and Behavior, 58: 605-608.

33. Thakkar M \& Mallick BN (1993). Effect of rapid eye movement sleep deprivation on rat brain monoamine oxidases. Neuroscience, 55: 667-683.

34. Mogilnicka E, Arbilla S, Depoortere $\mathrm{H} \&$ Langer SZ (1980). Rapid-eye-movement sleep deprivation decreases the density of ${ }^{3} \mathrm{H}$-dihydroalprenolol and ${ }^{3} \mathrm{H}$-imipramine binding sites in the rat cerebral cor- tex. European J ournal of Pharmacology, 65: 289-292.

35. Troncone LRP, Braz S, Benedito MAC \& Tufik $S$ (1986). REM sleep deprivation induces a decrease in norepinephrine-stimulated ${ }^{3} \mathrm{H}$-cyclic AMP accumulation in slices from rat brain. Pharmacology, Biochemistry and Behavior, 25: 223-225.

36. Szymusiak R (1995). Magnocellular nuclei of the basal forebrain: substrates of sleep and arousal regulation. Sleep, 18: 478500.

37. Losier BJ \& Semba K (1993). Dual projections of single cholinergic and aminergic brainstem neurons to the thalamus and basal forebrain in the rat. Brain Research, 604: 41-52.
38. Manns ID, Alonso A \& J ones BE (2000). Discharge properties of juxtacellularly labeled and immunohistochemically identified cholinergic basal forebrain neurons recorded in association with the electroencephalogram in anesthetized rats. J ournal of Neuroscience, 20: 1505-1518.

39. Baghdoyan HÁ, Spotts J L \& Snyder SG (1993). Simultaneous pontine and basal forebrain microinjections of carbachol suppress REM sleep. J ournal of Neuroscience, 13: 229-242.

40. Everitt BJ \& Robbins TW (1997). Central cholinergic systems and cognition. Annual Review of Psychology, 48: 649-684. 